\title{
The interaction between Sedum root traits and engineered media in green roofs
}

\author{
Xuan Chen, Ruifen Liu*, and Jun Ma
}

Hubei Provincial Key Laboratory of River and Lake Ecological Restoration and Algae Utilization, Innovation Demonstration Base of Ecological Environment Geotechnical and Ecological Restoration of Rivers and Lakes, School of Civil Engineering, Architecture and Environment, Hubei University of Technology, Wuhan 430068, Hubei, China

\begin{abstract}
Sedum sarmentosum and Sedum lineare, two common plants for green roof, were planted in two engineered media meeting FLL standards at three depths. Root characteristics of root length density, root surface area density, and root volume density were quantified. And a key hydraulic property, saturated hydraulic conductivity $\left(K_{\mathrm{s}}\right)$ values of the engineered media with and without plants were measured. The results showed that engineered media type, engineered media depth, and their interaction all have a significant impact on Sedum root traits. For the engineered media with Sedum, only engineered media type and depth had a significant effect on $K_{\mathrm{s}}$. When the type of engineered media was the same, with the same plant used, $K_{\mathrm{s}}$ of the engineered media at a depth of $14 \mathrm{~cm}$ was significantly smaller than $K_{\mathrm{s}}$ of any other depth. This can be attributed to the maximum level of RSD and RVD at the 14-cm depth. The reduction in $K_{\mathrm{s}}$ of the perlite-based engineered media due to plant roots is an important finding, as plant roots clog the pore spaces and lead to poor drainage and unexpected ponding in roofs. This research provides better understanding of the interaction between plant roots and engineered media in green roofs.
\end{abstract}

Keywords: Interaction; Sedum root traits; Engineered media; Saturated hydraulic conductivity; Green Roofs.

\section{Introduction}

Green roofs, as an important measure of source control and runoff control in sponge cities, have received widespread attention in recent years [1]. In modern green roof structures, plants and engineered media are two important functional layers. Plants ensure the ecological benefits of green roofs [2] and engineered media is the main site for water/solute movement. There is a close interaction between plants and engineered media.For example, plant roots can change the physical structure and hydraulic properties of engineered media, which in turn can affect the water movement within green roofs [3]. A Strong and well-developed root system would reduce the rainwater retention effect of green roofs due to preferential flow related to root-induced structure[4-5].The type and depth of engineered media are important factors affecting the growth of plants[6-7], which are closely related to

*Corresponding author: ruifen1986@aliyun.com 
plant above-ground biomass and survival rate[8]. It was found that plants grown in shallower substrate had better biomass accumulation in green roofs[9]. However, little is known about how engineered media affects plant root traits. As a key hydraulic property of engineered media, saturated hydraulic conductivity $\left(K_{\mathrm{s}}\right)$ is generally quantified without considering the role of plant roots [10]. The change in $K_{\mathrm{s}}$ due to the presence of plant roots remains largely unknown. In this study, Sedum sarmentosum and Sedum lineare, which are two commonly used plants in green roofs, were planted in two engineered media meeting FLL standards [11] at three depths. Root traits of length density, surface area density, and volume density were measured. $K_{\mathrm{s}}$ values of the engineered media with and without plants were also determined. The purposes of this study were to quantify the effects of engineered media type and depth on Sedum root traits and to compare $K_{\mathrm{s}}$ values of engineered media varying in type and depth with different root traits.

\section{Materials and methods}

\subsection{Sedum type and engineered media}

Two engineered media were developed by mixing aggregate and manure at a volume percentage of 9:1 (Table 1). The first engineered media mix used perlite aggregate and the second used vermiculite aggregate. Both engineered media were developed according to FLL standards, and their basic characteristics are listed in Table 1.

Table 1. Characteristics of the engineered media [mean (standard error)].

\begin{tabular}{ccc}
\hline Characteristics & Perlite-based mix & Vermiculite-based mix \\
\hline Components $(\%$ by volume $)$ & $90 \%$ perlite $(<6 \mathrm{~mm})$ & $90 \%$ vermiculite $(<5 \mathrm{~mm})$ \\
& $10 \%$ chicken manure & $10 \%$ chicken manure \\
Dry bulk density $(\mathrm{g} / \mathrm{cm})$ & $0.21(0.01)$ & $0.34(0.01)$ \\
Total porosity $(\%)$ & $91.40(0.01)$ & $78.80(0.02)$ \\
Maximum water-holding capacity $(\%)$ & $36.65(1.33)$ & $64.05(1.55)$ \\
Organic matter content $(\mathrm{g} / \mathrm{kg})$ & $31.15(2.72)$ & $38.64(2.60)$ \\
$K_{\mathrm{s}}(\mathrm{cm} / \mathrm{min})$ & $54.45(0.19)$ & $18.48(1.39)$ \\
\hline
\end{tabular}

Sedum sarmentosum and Sedum lineare were chosen for this study for their wide application in extensive green roofs [12-14]. Considering that Sedum plants are shallow-rooted species with weak edge effects [15], acrylic cylinders configured with perforated bases for drainage, and of $10-\mathrm{cm}$ diameter and $15-\mathrm{cm}$ height, were used for indoor small-scale cultivation. Plant cultivation involved 12 treatments, including two types of plants (Sedum sarmentosum and Sedum lineare), two types of engineered media (perlite-based mix and vermiculite-based mix), and three engineered media depths $(6,10$, $14 \mathrm{~cm}$ ). Each treatment had three replicates, making 36 samples in total.

In each sample, Sedum cuttings were planted at a spacing of $2 \mathrm{~cm} \times 2 \mathrm{~cm}$. Thereafter, samples were put into an artificial climate chamber (Shanghai Yiheng MGC400H) and subjected to a typical climate in Wuhan City. The temperature was maintained at $25{ }^{\circ} \mathrm{C}$, relative humidity was set between $40 \%$ and $50 \%$ and a daily photoperiod of 10:14 h (L:D) was scheduled [16]. In addition, $85 \mathrm{~mL}$ water was regularly applied to each sample every 3 days. After 103 days, samples were taken out for the measurements of root traits and $K_{s}$. 


\subsection{Measurement of Sedum root traits}

Before measurement, the roots were cleaned and plucked using brushes and forceps to minimize crossover and overlap. Root images were obtained by a German PMT-RTP-A3 root system scanner (the pixel setting was $600 \mathrm{dpi}$.). Scanned images were then analyzed by the Root Analysis system to obtain various root traits including root length density (RLD, $\mathrm{mm} / \mathrm{cm}^{3}$ ), root surface area density $\left(\mathrm{RSD}, \mathrm{mm}^{2} / \mathrm{cm}^{3}\right.$ ), and root volume density (RVD, $\left.\mathrm{mm}^{3} / \mathrm{cm}^{3}\right)$.

\subsection{Measurement of $K_{s}$}

The $K_{s}$ values were measured according to the falling-head method specified by the FLL standard [11], before being taken out of plants in samples for root trait measurement. The detailed steps were as follows. After cutting off the above-ground part of Sedum, samples with various depths $(\mathrm{H}, \mathrm{cm})$ were submerged in water for at least $24 \mathrm{~h}$ and then left to drain for up to $2 \mathrm{~h}$. A two-pronged metal ring was placed on the tops of the samples. Water was continually added to the tops of the samples until a constant water level was maintained on the tops and water drained freely out of the perforated bottoms. $K_{\mathrm{s}}$ was then calculated based on the time $(\mathrm{t}, \mathrm{s})$ taken for the water level to drop from the $45 \mathrm{~mm}$-prong to the 35 mm-prong: $K_{\mathrm{s}}(\mathrm{cm} / \mathrm{s})=\mathrm{H} /(\mathrm{H} \cdot \mathrm{t}+0.4 \mathrm{t})$.

\subsection{Statistical analysis}

All data analyses were performed in IBM SPSS Statistics 26.0. Effects of engineered media type and depth on Sedum root traits and $K_{s}$ comparison of engineered media with various root traits were analyzed using a two-way analysis of variance (ANOVA). Statistical differences between compositions were assessed at the $P<0.05$ level of significance by t-test (for a comparison between two) or LSD post hoc test (for a comparison between three). Data were checked for normality and were transformed appropriately (using the Box-Cox transformations) where necessary before analysis. All data presented in figures and tables were non-transformed.

\section{Results and discussion}

\subsection{Effects of engineered media type and depth on Sedum root traits}

For the RLD of Sedum sarmentosum, engineered media type $(F=259.97, P<0.01)$, engineered media depth $(F=366.39, P<0.01)$, and their interaction $(F=150.10, P<0.01)$ all showed significance, indicating that the two factors jointly influenced the changes in the RLD [Fig. 1(a)]. The RLD of $9.60 \mathrm{~mm} / \mathrm{cm}^{3}$ in the $6-\mathrm{cm}$ vermiculite-based engineered media was the largest. Similar to Sedum sarmentosum, engineered media type $(F=477.10$, $P<0.01)$, engineered media depth $(F=1672.86, P<0.01)$, and their interaction $(F=258.33$, $P<0.01)$ resulted in significant differences in the RLD of Sedum lineare. The largest RLD was recorded in $6-\mathrm{cm}$ vermiculite mixed engineered media, at $10.52 \mathrm{~mm} / \mathrm{cm}^{3}$. The RLD is the length of the root system contained per unit volume of a growing media and reflects the degree of root extension and interweaving within the media [17]. It is generally accepted in soil science that the deeper the soil, the more extensive the plant roots $[18,19]$. This is because deeper soils can not only provide more water/fertilizer for plant growth but also maintain a more stable temperature beneficial for plant root growth [20]. However, in this study, these media depth-related benefits for plant growth were rather limited by a narrow media depth range of $6 \mathrm{~cm}$ to $14 \mathrm{~cm}$. As a result, the RLD was greatest at a minimum media 
depth of $6 \mathrm{~cm}$. The results of Lu et al [8], who studied the impacts of media depth on the morphology of Sedum lineare in a green roof system, also showed that the growth of root length in a shallow media of $4 \mathrm{~cm}$ was greater than the growth in a $10 \mathrm{~cm}$ media.
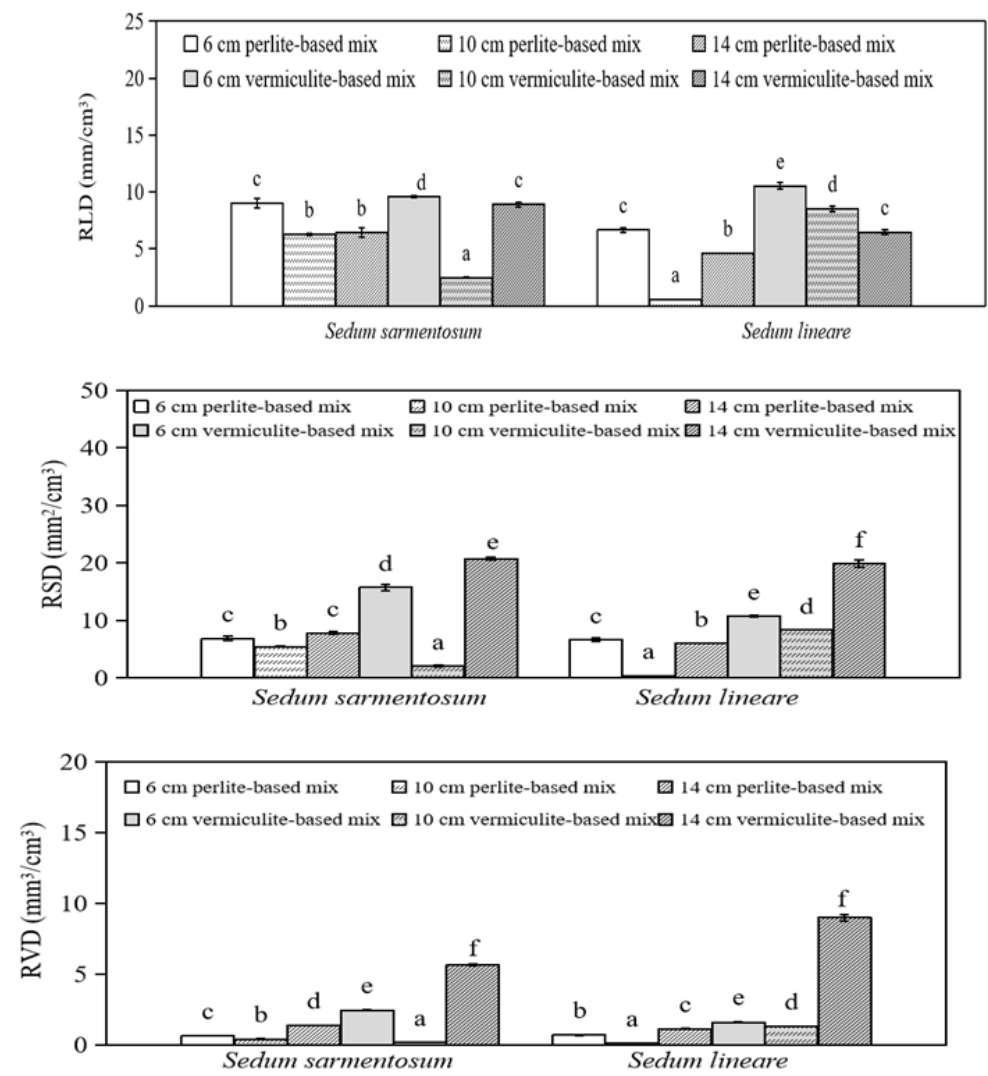

Fig. 1. Root length density (a), root surface area density (b), and root volume density (c) of Sedum plants within each treatment. Where there is a significant interaction, lowercase letters denote significant differences between all means within the same plant.

With regards to the RSD of Sedum sarmentosum, engineered media type ( $F=1172.44$, $P<0.01)$, engineered media depth $(F=1206.85, P<0.01)$, and their interaction $(F=742.56$, $P<0.01)$ all showed significance, indicating that the two factors both influenced the changes in the RSD together [Fig. 1(b)]. The RSD was the largest $\left(20.76 \mathrm{~cm}^{2} / \mathrm{cm}^{3}\right)$ in the $14-\mathrm{cm}$ vermiculite-based engineered media and was at least 1.31 times greater than any other group. As with Sedum sarmentosum, engineered media type $(F=925.65, P<0.01)$, engineered media depth $(F=2780.13, P<0.01)$, and their interaction $(F=297.69, P<0.01)$ resulted in significant differences in the RSD of Sedum lineare. The RSD was highest $\left(19.91 \mathrm{~cm}^{2} / \mathrm{cm}^{3}\right)$ and at least 1.84 times greater than any other group in the 14-cm vermiculite-based engineered media.

For the RVD of Sedum sarmentosum, engineered media type $(F=9635.87, P<0.01)$, engineered media depth $(F=8910.10, P<0.01)$, and their interaction $(F=4375.87, P<0.01)$ all exhibited significance, indicating that the two factors jointly influenced RVD changes [Fig. 1(c)]. The RVD was the largest $\left(5.66 \mathrm{~cm}^{3} / \mathrm{cm}^{3}\right)$ in the $14-\mathrm{cm}$ vermiculite-based engineered media and was at least 2.31 times greater than any other group. Comparably to Sedum sarmentosum, engineered media type $(F=19549.06, P<0.01)$, engineered media depth $(F=10016.15, P<0.01)$, and their interaction $(F=1889.29, P<0.01)$ all resulted in 
significant differences in the RVD of Sedum lineare. The maximum level of RVD (8.99 $\mathrm{cm}^{3} / \mathrm{cm}^{3}$ ) was recorded in the $14-\mathrm{cm}$ vermiculite-based engineered media, which was at least 5.62 times greater than any other group. The RSD and RVD can indicate the contact area between the root system and the engineered media [21], and together with RLD, can reflect the root traits. The 14-cm vermiculite-based engineered media had the largest RSD and RVD but a relatively smaller RLD, suggesting that media depth-related benefits for plant roots are embodied by RSD and RVD. In this case, the Sedum root system limited RLD development but promoted RSD and RVD development to obtain more water and nutrients in the shallow depth environment.

\section{$3.2 K_{\mathrm{s}}$ comparison of engineered media with various root traits}

For the engineered media with Sedum, the engineered media type and depth had a significant effect on $K_{\mathrm{s}}$, but their interaction had no significant effect (Figure 2). The role of media type and depth on $K_{\mathrm{s}}$ is expected, as the media type and depth had an impact on the root traits (Section 3.1). The fact that the interaction of media type and depth is significant for Sedum root traits but not for $K_{\mathrm{s}}$, indicates that this interaction is not big enough to change $K_{\mathrm{s}}$. As shown in Figure 2, when the depth of the engineered media was the same, with the same plant, $K_{\mathrm{s}}$ in the perlite-based engineered media was significantly smaller than that in the vermiculite-based engineered media. $K_{\mathrm{s}}$ in plants in the perlite-based engineered media ranged from $0.568-2.641 \mathrm{~cm} / \mathrm{min}$ with a mean value of $1.455 \mathrm{~cm} / \mathrm{min}$, while $K_{\mathrm{s}}$ in the plants in the vermiculite-based engineered media ranged from $12.77-19.19 \mathrm{~cm} / \mathrm{min}$ with a mean value of $15.39 \mathrm{~cm} / \mathrm{min}$. The latter result was therefore about $6.42-22.72$ times higher than the former. When the type of engineered media was the same, with the same plant, $K_{\mathrm{s}}$ of the engineered media at a depth of $14 \mathrm{~cm}$ was significantly smaller than $K_{\mathrm{s}}$ of any other depth. This can be attributed to the maximum level of RSD and RVD recorded in the 14-cm depth (Section 3.1). A potential negative correlation exists between $K_{\mathrm{s}}$ and RSD/RVD.

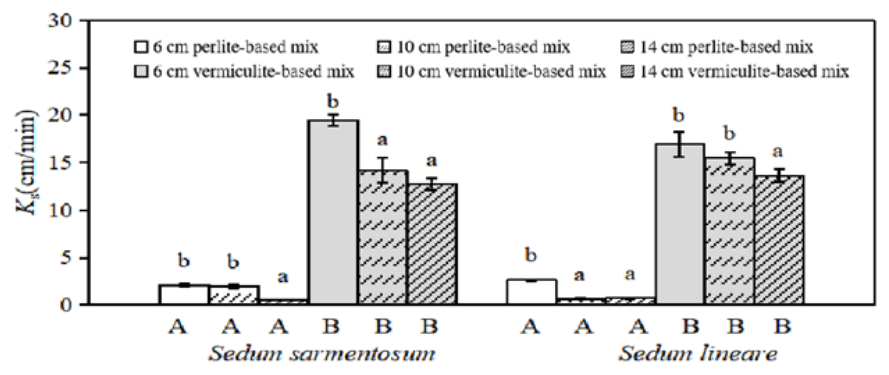

Fig. 2. Saturated hydraulic conductivity of engineered media with Sedum. Where there is no significant interaction, uppercase letters denote significant differences between engineered media types and lowercase letters denote significant differences between engineered media depth.

Compared with perlite-based engineered media without plants (Table 1), $K_{\mathrm{s}}$ of perlite-based engineered media with plants were significantly smaller and had a greater variation. It is well known that plant roots can significantly reduce $K_{s}$ by up to $143 \%$ [22]. Our study found similar results as the presence of roots in the perlite-based engineered media resulted in a reduction in $K_{\mathrm{s}}$ of over $95 \%$. This may be due to the hard texture of perlite particles. Without changing the existing positions of perlite particles, Sedum roots can only grow along the curved interparticle paths [23], which reduces the total porosity and decreases the $K_{\mathrm{s}}$ of engineered media [24]. The reduction in $K_{\mathrm{s}}$ of the perlite-based engineered media due to plant roots is noteworthy, as plant roots would clog the pore spaces and lead to poor drainage and unexpected ponding in roofs. As for the vermiculite-based engineered media, there was no significant difference in $K_{\mathrm{s}}$ between the 
plant group and the no-plant group. The above results indicate that depending on engineered media type, changes in $K_{\mathrm{s}}$ due to plants roots can vary remarkably.

\section{Conclusions}

Engineered media type, engineered media depth, and their interaction all showed significance on Sedum root traits. For the engineered media with Sedum, only engineered media type and depth had a significant effect on $K_{\mathrm{s}}$, indicating that this interaction could only change the Sedum root traits, but it is not big enough to change $K_{\mathrm{s}}$. When the depth of the engineered media was the same, with the same plant, $K_{\mathrm{s}}$ in the perlite-based engineered media was significantly smaller than that in the vermiculite-based engineered media. When the type of the engineered media was the same, with the same plant, $K_{\mathrm{s}}$ of the engineered media at a depth of $14 \mathrm{~cm}$ was significantly smaller than $K_{\mathrm{s}}$ of any other depth. This can be attributed to the maximum value of RSD and RVD in the 14-cm depth. A potential negative correlation exists between $K_{\mathrm{s}}$ and RSD/RVD. Compared with perlite-based engineered media without plants, $K_{\mathrm{s}}$ of perlite-based engineered media with plants were significantly smaller. The presence of roots in the perlite-based engineered media resulted in a reduction in $K_{\mathrm{s}}$ of over $95 \%$. As for the vermiculite-based engineered media, there was no significant difference in $K_{\mathrm{s}}$ between the plant group and the no-plant group. The above results indicate that depending on engineered media type, changes in $K_{\mathrm{s}}$ due to plants roots can vary remarkably.

Future work should focus on the study of other hydraulic properties of engineered media induced by roots in green roofs. This will better understand the water transport process of green roofs in sponge city construction.

\section{Acknowledgements}

The work is supported by the National Natural Science Foundation of China (51909081 and 5217090897).

\section{References}

1. M. Xiao, Y. Lin, J. Han, Renewable and Sustainable Energy Reviews, 40 (2014)

2. K. Vijayaraghavan, Renewable and Sustainable Energy Reviews, 57 (2016)

3. A. Skorobogatov, J He, A Chu, Sci Total Environ, 715 (2020)

4. Z Zhang, C. Szota, T.D. Fletcher, Nicholas S.G. Williams, J. Werdin, C. Farrell, Sci Total Environ,625 (2018)

5. Y.C. Hu ,H.P. Qin , Z.X.Lin, Journal of Shenzhen University(Science \& Engineering), 37 (2020)

6. C.Brown, J.Lundholm, Landscape \& Urban Planning, 143 (2015)

7. J.Chenot, E.Gaget, C.Moinardeau, Multidisciplinary Digital Publishing Institute, 9 (2017)

8. J. Lu, J.G. Yuan, J.Z. Yang,Ecological Engineering, 74 (2015)

9. J. Lu, J.G. Yuan, J.Z. Yang,Urban Forestry \& Urban Greening, 13 (2014)

10. S.L. Peng, W.H. You, H.T. Shen, Transactions of the Chinese Society of Agricultural Engineering, 26 (2010) 
11. FLL. Duidelines for the Planning, Construction and Execution of green-roof site(Germany Troisdorf: Forschungsgesellschaft Landschaftsentwicklung Landschaftsbau e.V, 2008)

12. T. Luo, W.N. Xu, H. Cheng, Environmental Engineering, 38 (2020)

13. S.X. Zhang, S.H. Zhang, Y. Zhang, Environmental Science, 40 (2019)

14. T. Li, Y.L. Chen, J.Q. Gu, Journal of Tongji University(Natural Science), 43 (2015)

15. Y. Dusza, S. Barot, Y. Kraepiel, Ecol Evol, 7 (2017)

16. M.H. Yu, P. Zhao, C.P. Ceng, Guihaia, 32 (2012)

17. J.X. Li, B.H. He, Y.Chen, Transactions of the Chinese Society of Agricultural Engineering, 29 (2013)

18. S. Tron, G. Bodner, F. Laio, Ecol Modell, 312 (2015)

19. K.L. Getter, D.B. Rowe, Urban Ecosystems, 11 (2008)

20. L.H. Comas, S.R. Becker, V. Cruz, Frontiers in Plantence, 4 (2013)

21. J.X. Li, B.H. He, Y.Chen, Acta Ecologica Sinica, 33 (2013)

22. J. Lu, Q. Zhang, A.D. Werner, Journal of hydrology (Amsterdam), 589 (2020)

23. A.G. Bengough , B.M. Mckenzie , P.D. Hallett, Journal of Experimental Botany, 62 (2011)

24. N. Koebernick, K.R. Daly, S.D. Keyes, New Phytologist, 216 (2017) 